for the cost of the "year out" to be split between the departments which will benefit from the trainees presence in the other four years.

The final approval of training departments and of training programmes is done by the JCHTA\&E, but they will only inspect a post or scheme if it has been recommended by the regional $A \& E$ higher training committee.

The regional $A \& E$ higher training committee will make recommendations on the distribution of trainees and this should be on educational grounds alone, but they will not recommend a department for training if there is no prospect that the post can be funded. It is necessary to make out a case for the experience and training which you can provide. Write out a prospectus for the committee giving full details of staffing, numbers of patients, teaching, audit, research, recent publications, etc. Provide a timetable for the trainee. You should also be asked to attend the committee to present this. Drawing up this prospectus will not be time wasted as it can also be used for the application to the JCHTA\&E.

Once the regional higher training committee has recommended that you are allocated a specialist registrar, write to the JCHTA\&E asking for an application form and in due course you will be visited by two members of the JCHTA\&E who will wish to inspect the facilities in the department and hospital, to talk to you and to junior staff working in your department, and they may also want to talk to consultants in other acute specialties. Do not expect an instant answer! The visitors draw up a report which will be discussed at the next meeting of the JCHTA\&E. Only then will you receive approval for your post. This will hopefully be for five years but if there are any problems, they may give approval for a shorter time.

Once you have been given approval, you will be given a training number for the post. It is quite possible that a long time has passed since you first tried to get a specialist registrar and you may need to amend the job description that was correct 12 months earlier. You will also need to draw up a person specification. In my own region every job description and timetable has to be approved by the regional specialist training committee before a job is advertised, which adds another few weeks to the delay but at long last the moment arrives when you see the advertisement for your trainee post in the BMJ.

Plymouth

H R GULY

1 Board of the Faculty of Accident and Emergency Medicine. Guidelines for specialist training in accident and emergency medicine. London: Faculty of Accident and Emergency Medicine, 1996.

2 Department of Health. A guide to specialist registrar training. London: $\mathrm{DoH}$, 1996.

\title{
Choosing an accident and emergency department computer
} \section{system}

We are all aware of the phenomenal development over the last few years in information technology. Unfortunately its introduction into the NHS has been far from smooth and examples of expensive disasters are well known.

Our specialty more than any other needs the help of computer technology because of the large numbers of patients we process. Accurate information is essential to survive in the present day NHS with its constricting cash limits. Anecdotal evidence is no longer acceptable when making bids for resources.

Unfortunately many of the A\&E systems which have been introduced in the past have had a very limited capability. The recent report from the Audit Commission on improving $A \& E$ services in England and Wales criticised many of the computer systems as being either inflexible or inadequate, producing incomplete data, lack of validation of data, and having poor links between the $A \& E$ computer and other hospital systems.

Seven years ago I was persuaded to "computerise" the A\&E department of this hospital. I had no previous experience of computers either at home or at work and what follows is an account of the lessons learnt on the way!

\section{Type of system}

There are really three choices: (1) a stand alone system; (2) stand alone but interfaced with the hospital PAS (patient administration system); (3) an $A \& E$ module of a hospital information system (HIS).

STAND ALONE SYSTEM

In many ways the stand alone system is the most appropriate for an $A \& E$ department. We work very differently from other departments in the hospital and no two departments work in exactly the same way, so flexibility in the system is essential. An accident department has to be "live" 24 hours a day every day of the year. It can be very annoying if the $\mathrm{A} \& \mathrm{E}$ system goes down every time the hospital system goes down, particularly if this is just for a period of back up.

Stand alone systems are now very reliable and many are capable of carrying out back up procedures while still operating. Unfortunately stand alone systems are not popular with hospital information departments who like to feel they "control" all the systems in the hospital.

STAND ALONE INTERFACED WITH HOSPITAL PAS

Stand alone systems interfaced with hospital PAS systems are probably the compromise solution for most hospitals. They have the advantage of being able to use a single patient number throughout the hospital whichever department the patient presents to. Unfortunately interfacing is expensive and sometimes difficult, and it often depends on goodwill between the various suppliers. The Audit Commission report also pointed out two quite major disadvantages where $A \& E$ computers are linked to hospital systems. In one hospital where the $A \& E$ system was linked to the PAS module it took up to seven minutes to produce an $A \& E$ card at times when other hospital systems were being heavily used. At another hospital computer, "down time" had increased markedly when the A\&E system had been linked to the PAS. A good interface should get round both these problems.

A\&E MODULE OF HOSPITAL INFORMATION SYSTEM

The A\&E modules of hospital HIS systems are often very unsatisfactory. They have often been thrown together with little involvement of $A \& E$ expertise and may have been offered as a "freebie" to the hospital management if they take a particular HIS system for their hospitals.

They are never flexible and any attempt to make changes to them is often met with resistance or incurs great expense. Many $A \& E$ consultants who have been forced to 
take these systems into their departments have found them very unsatisfactory. I suspect many of the systems criticised in the Audit Report fall into this category.

\section{Choosing your supplier}

Before choosing a system from a particular supplier you should sit down and think hard and long about what you want the system to do. Computer systems are very versatile but can also be full of gimmicks. It is no good having a system operating on light pens if the underlying software is inadequate. If the particular function offered is of no benefit either to your patients or your staff why include it? What is useful in one department may not be useful in another. Obviously certain functions, for example patient registration, are going to be common to all systems but you do not want to end up with a system which makes you operate in a way you find unacceptable.

Some guiding principles for the software application are:

(1) It must obviously carry out all the essential requirements of the department. This will vary between departments but will include:

(a) Patient registration;

(b) Pre- or postregistration triage;

(c) Clinic bookings;

(d) GP letters;

(e) Patient inquiry system;

(f) Management information system-including current register of patients and Patients' Charter information.

(2) It must be user friendly. Some staff will always be resistant to the introduction of computer systems but my experience has been that once the staff are familiar with the system they would not be without it. The first six to eight weeks after introduction of a system is often very difficult. Some systems are much more user friendly than others. If the system is really user friendly then it should be possible to train a new receptionist (given existing keyboard skills) within two to three hours.

It should also be easy to introduce new codes into the system yourself. It becomes very frustrating if every time you want to introduce a new code you have to go back to the software house to do this.

(3) It must be flexible. Lack of flexibility was a major criticism of the Audit Commission report. No system will give you everything you want and some compromises do have to be made. However, you will want to add and subtract items from time to time and on the whole it is much easier, and less expensive, to do this with a stand alone system than with a module of a hospital HIS system. In my opinion flexibility of the system is one of the most important features you should be looking for.

(4) A good reporting system is essential. Again access to good reports in-house is not always a feature of some systems. Many standard reports, for example RTA register, Patients' Charter information, at-risk register, management information, etc, should be immediately available on standard reports. The ability to construct ad hoc reports is also now a feature of some systems and this can often be done on a single screen and is invaluable for research and audit purposes.

The software you eventually choose will probably determine the hardware you use in the department. You should listen carefully to your supplier about this as he will probably recommend that a particular software application runs best on certain hardware.

Having decided what you want your system to do it is then essential to go and look at the system operating in an $A \& E$ department. It is not satisfactory only to see "demonstrations" by the supplier, you need to go and see the system operating live and talk to the staff using it to assess its user friendliness and flexibility. Suppliers often say "yes, it can do this or that" when asked, but the actual software is not yet written.

\section{Designing the system for your department}

The actual design will depend on the geography of your own department. Decide how many stations you require, and even if the finance is not available to put all these stations in immediately at least carry out the necessary wiring at stage 1 . It is much more expensive and inconvenient to go back later and have to put in more wiring when you want to add further stations. In my own department we were wired for 14 sites initially but only put in seven stations; this has now increased to 12 .

Remember to connect the departmental computer and at least one patient station to the emergency power supply. In the event of an electrical shutdown it is no help to have your computer functioning if you cannot print out the patients' notes!

Hardware failures are becoming less frequent but do still occur. PCs, VDUs, and printers do fail from time to time and it is important that essential pieces of equipment in the department are duplicated. The booking-in station at Reception and also the patient note printer should be duplicated as a minimum.

Depending on the layout of individual departments, there are advantages to having the patient note printers located where the patients are seen, rather than in the reception area. It can produce a saving on waiting time of up to 10 minutes per patient if nurses are not continually going backwards and forwards to Reception to pick up notes.

\section{Service agreement}

Computers on the whole are now very reliable but you will need a service agreement both for the software system and hardware. You will have to choose the type of service you require, but for an $A \& E$ system service within four hours is fairly essential and this can be quite expensive.

\section{Coding}

In my view the $A \& E$ specialty as a whole has made a big mistake in the past in not adopting an international coding system. The inadequacies of many $A \& E$ systems highlighted in the Audit Commission report relate to this defect and many local coding systems which have been introduced in the past are totally inadequate.

It is often argued that adopting an international coding system is too complicated for an $\mathrm{A} \& \mathrm{E}$ department but I have not found this to be the case. In my own department we have used ICD 9 coding and are shortly hoping to transfer to Read Coding. It is perfectly possible to extract from these international coding systems the conditions commonly seen in an A\&E department. Lists of these codes are kept freely available within the department and are also available as a prompt on the computer system. The adoption of an international code within the departments has many advantages, not least of which are the ability to compare audits between departments and also to produce useful GP letters. In the system I use it takes an SHO just over a minute to put in the necessary codes to produce the GP letters, and it is amazing how quickly the commonly used codes are memorised. When we started using the codes to produce GP letters the accuracy of the coding went up from $72 \%$ to $95 \%$ almost overnight.

I think it is high time the A\&E specialty caught up with the rest of our colleagues in using an international coding system. 


\section{Installation and training}

When you have chosen the system you are going to use then careful thought should be given to installation and training. My advice would be to choose five or six key people in the department, train them to be totally familiar with the system, and then use them to cascade down to other members of staff.

It is also a good idea to have the system installed then allow the staff to "play" with it for a time before it becomes a live system. If it is a user friendly system they will rapidly realise that many of their fears were unfounded and will quickly become enthusiastic about wanting to get the system on the road. There is a great temptation to start using the system as soon as it is installed, but in my view a period of familiarisation can avoid many initial problems.

It is also best not to try to introduce all the functions of the computer immediately. Start off with patient registration and then add the other functions as and when the staff are happy with their progress. It is also a good idea to keep some of your paper systems running side by side with the computer for a short time after you go live. This gives the staff a lot of confidence as they know that if they make a mistake the information is still available.

One of the most important factors when installing a computer system is a very strong, enthusiastic consultant lead. If this is not present the full benefits of the system will not be realised.

You can expect a fairly turbulent first two months but after that you will be surprised how quickly the attitudes change. I heard the classic comment from one member of staff after six weeks: "isn't it good, the computer has settled down"!

B C ELVIN

Basingstoke
- Disciplinary procedures I P Stewart

- Managing a bed crisis $\mathcal{f}$ T Egan

- Audit in the accident and emergency department T D Llewellyn

- Organising training for undergraduates and SHOs f N Rawlinson
- How to conduct an SHO appraisal $M$ f Clancy

- Purchasing new equipment $C D$ H Oakland

- Organising a medical conference $\mathcal{F}$ Wyatt

- Dealing with the police $P A W H$ Howarth 